\title{
Contribuição da literatura sobre a temática violência e saúde nos 25 anos da Ciência \& Saúde Coletiva
}

\author{
Contributions to the literature on violence and health in 25 years \\ of the Brazilian public health Ciência \& Saúde Coletiva
}

Edinilsa Ramos de Souza (https://orcid.org/0000-0003-0903-4525) ${ }^{1}$

Liana Wernersbach Pinto (https://orcid.org/0000-0003-1928-9265) ${ }^{1}$

Kathie Njaine (https://orcid.org/0000-0003-3250-2331) ${ }^{1}$

Adriano da Silva (https://orcid.org/0000-0002-1105-9046) ${ }^{1}$

${ }^{1}$ Departamento de Estudos sobre Violência e Saúde Jorge Careli, Escola Nacional de Saúde Pública Sergio Arouca, Fiocruz. Av. Brasi 4036/700, Manguinhos. 21040-361 Rio de Janeiro RJ Brasil.

edinilsaramos@gmail.com

\begin{abstract}
The authors conducted a literature review on the theme of violence and health published in the Brazilian public health journal "Ciência \& Saúde Coletiva” (CesSC) from 1996 to 2019. The search also included two other Brazilian journals, "Cadernos de Saúde Pública" (CSP) and "Revista de Saúde Pública" (RSP) and two international journals, the "American Journal of Public Health" $(A J P H)$ and the "Pan American Journal of Public Health" (PAJPH), totaling 1,179 articles. The analysis aggregated each journal's material in eleven themes, based on conceptual affinity. For the articles from C\&SC, the authors analyzed variables such as year of publication, area of knowledge, institution's region, study scope, methodology, and target population. The analysis found that $C \mathrm{rSC}$ gave visibility to violence and health, standing out from the other journals since 2009. External causes, children and adolescents, quantitative studies, municipal and national scope, and institutions located in the Southeast region of Brazil predominated. There are gaps in topics such as self-mutilation and vulnerable populations, among other areas where more studies and publications should be encouraged.
\end{abstract}

Key words Violence, External causes, Intrafamily violence, Information systems, Health services
Resumo Realizou-se uma revisão da literatura sobre a temática violência e saúde publicada na revista Ciência \& Saúde Coletiva/RCひSC, no período de 1996 a 2019. A busca também incluiu dois periódicos nacionais (Cadernos de Saúde Públical CSP e Revista de Saúde Pública/RSP) e dois internacionais ("American Journal of Public Health/ AJPH" e "Pan American Journal of Public Health/ PAJPH"), totalizando 1.179 artigos localizados. A análise agregou o acervo de cada periódico em onze temas, segundo afinidade conceitual. Para os artigos da CeSC foram analisadas variáveis como: ano da publicação, área do conhecimento, região da instituição, abrangência do estudo, método empregado e população alvo. A análise identificou que a revista deu visibilidade à temática, destacando-se dos demais periódicos a partir de 2009. Causas externas, grupo de crianças e adolescentes, estudos quantitativos, com abrangência municipal e nacional e instituições localizadas na região Sudeste preponderaram. Há lacunas de temas relevantes como automutilação, populações vulneráveis, entre outros, sobre os quais se deveriam incentivar estudos e publicações.

Palavras-chave Violência, Causas externas, Violência intrafamiliar, Sistemas de informação, Serviços de saúde 


\section{Introdução}

Em 1993 a Organização Pan-Americana da Saúde/OPAS lançou uma resolução sobre a problemática da violência e saúde e, em 1994, um Plano para as Américas visando a sua prevenção ${ }^{1,2}$. Em 1996, a Organização Mundial de Saúde/OMS, em sua $49^{\mathrm{a}}$ assembleia, adotou a violência como um grave problema de saúde pública, e instou os países membros a desenvolver suas políticas e ações em relação ao tema.

Cinco anos mais tarde, o Ministério da Saúde do Brasil propôs sua Política Nacional de Redução da Morbimortalidade por Acidentes e Violência/PNRMAV ${ }^{3}$. Desde então, passou a investir em programas de prevenção da violência e promoção da saúde, visando a redução das lesões e mortes provocadas por eventos violentos ${ }^{4}$. Para isso, expandiu e criou serviços para atender as pessoas em situação de violência, orientou e sensibilizou a população, e capacitou profissionais do Sistema Único de Saúde/SUS. No âmbito da vigilância epidemiológica, melhorou a qualidade dos dados nos sistemas oficiais de informações e desenvolveu novos sistemas sobre o tema, acumulando, assim, um cabedal de conhecimentos sobre a violência no âmbito da saúde, dentre outras iniciativas.

No período de 20 anos o país viu crescer o número de grupos de pesquisa e de profissionais voltados para pesquisar, capacitar-se e atuar junto a pessoas e coletivos mais vulneráveis às violências interpessoal, comunitária e estrutural. Com isso, deu-se visibilidade ao tema em geral e às suas especificidades, divulgando o conhecimento em fóruns e publicações da área da saúde pública.

O objetivo deste artigo foi realizar uma revisão das publicações da revista Ciência \& Saúde Coletiva/C\&SC sobre o tema da violência e acidentes no percurso dos seus 25 anos, buscando identificar a magnitude dessa produção, os temas e os grupos mais presentes, bem como as lacunas em relação à temática.

\section{Metodologia}

Trata-se de uma revisão da literatura publicada na revista Ciência \& Saúde Coletiva/C\&SC sobre a temática da violência e acidentes, no período de 1996 a 2019.

Foram buscados como descritores os termos violência ou seus correlatos: abuso, maltrato, maus-tratos, agressão, violência étnica, conflito, preconceito, discriminação, desigualdade, homicídio, suicídio, acidentes, causas externas, homofobia. Tais termos foram pesquisados de modo geral ou associados a grupos específicos (criança, adolescente, mulher, idoso, deficiente, indígena, afrodescendente, $\mathrm{LGBTI}^{+}$), em línguas portuguesa e inglesa. Foram lidos títulos, resumos e palavras chave, para verificar a pertinência ao tema. Incluíram-se apenas os acidentes de transporte terrestre/ATT, por sua magnitude e letalidade, excluindo-se todos os acidentes. Artigos duplicados e de opinião, editoriais, resenhas e os que não abordavam violências ou ATT foram excluídos.

Buscou-se fornecer um painel geral do acervo publicado, analisando variáveis como temas e subtemas, área do conhecimento, região da instituição, abrangência do estudo, método empregado e população estudada. Para a análise, o acervo foi classificado em onze temas. Alguns deles já consagrados na literatura, como causas externas, violência intrafamiliar, violência de gênero, transtornos mentais, notificação/monitoramento e vigilância, violência e escola, criminalidade e delinquência, violência nas mídias. Outros artigos foram agrupados em temas segundo similaridade conceitual, como atenção a pessoas em situação de violência, estudos teóricos/metodológicos e violência social em geral.

A fim de comparar como se deu a produção sobre o tema em outros importantes periódicos da área, empregou-se a mesma estratégia de busca e classificação do acervo. Foram selecionados: Cadernos de Saúde Pública/CSP e Revista de Saúde Pública/RSP, American Journal of Public Health/AJPH, Pan American Journal of Public Health/PAJPH.

Após exclusões, o acervo analisado foi de 374 artigos na C\&SC. Além desses, foram localizados 237 artigos nos CSP, 155 na RSP, 292 no AJPH e 121 no PAJPH, totalizando 1.179 artigos analisados.

\section{Resultados}

No ano de 1999 a Revista C\&SC publicou o número temático $E$ possível prevenir a violência? Após esse número inaugural, as publicações sobre o tema nos anos seguintes se deram de forma tímida, com 10 artigos em 2005, e 15 em 2006, quando novo número temático foi lançado. A partir de 2009 se observou aumento substancial das publicações, com picos nesse ano e em 2017.

O Gráfico 1 mostra que o tema da violência foi objeto de publicações ao longo de todo perío- 
do pelos cinco periódicos analisados, com maior concentração a partir da metade da primeira década dos anos 2000. No entanto, observa-se que a revista C\&SC apresenta comportamento diferente dos demais, com maior volume de publicações em todos os anos desde 2009, exceto em 2014, quando foi superada pelo AJPH.

Nos periódicos internacionais, destaca-se a produção do $A J P H$, que publicou anualmente 10 ou mais artigos sobre violência, na maior parte do período, totalizando 292 artigos. O PAJPH publicou 121 artigos, com maior volume nos anos de 1999 (14 artigos) e 2015 (13 artigos) (Gráfico 1).
Na Tabela 1 observa-se que o principal tema publicado nos periódicos foram as causas externas, exceto na RSP, na qual predominou a violência intrafamiliar. É interessante notar que o tema atenção às pessoas em situação de violência tem um espaço relevante na C\&SC. Destaque deve ser dado ao tema da violência de gênero, que aparece como segundo tema mais publicado nos CSP e AJPH. Os demais temas mostraram distribuição heterogênea e menos frequente nas publicações.

$\mathrm{Na}$ Tabela 2 caracteriza-se o acervo sobre violência publicado na C\&SC. Parte importante dos trabalhos envolveu parcerias entre instituições de duas ou mais regiões do país. Instituições da

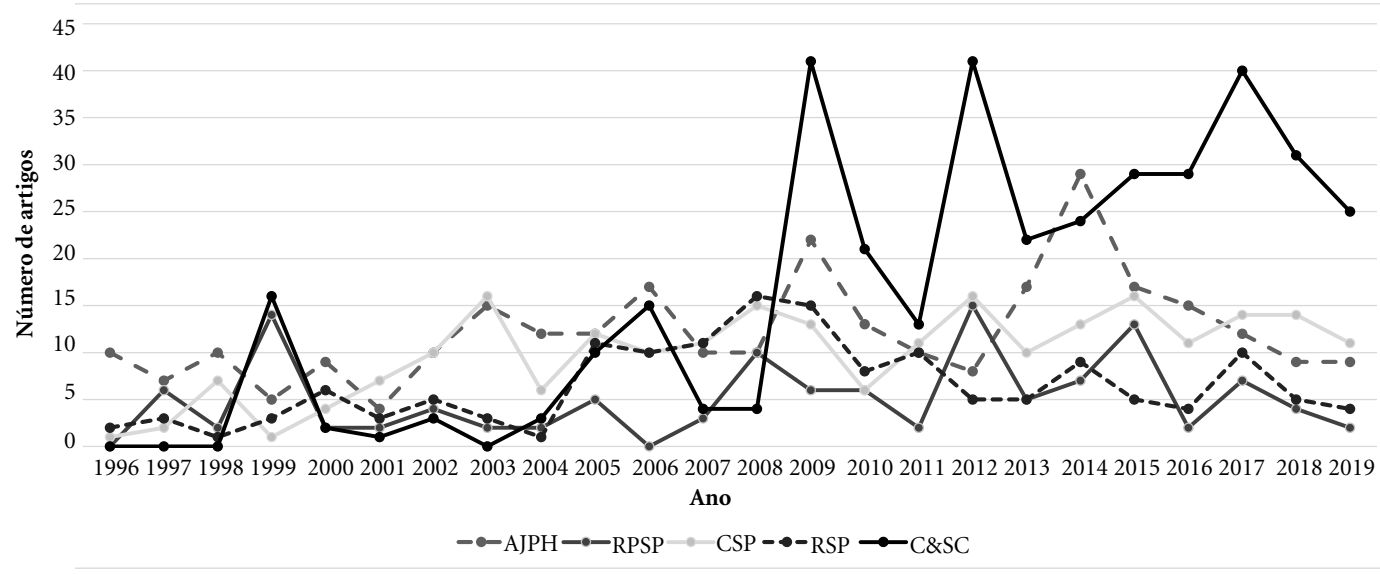

Gráfico 1. Distribuição das publicações sobre violência em revistas nacionais e internacionais de saúde pública selecionadas, no período de 1996 a 2019.

Tabela 1. Distribuição dos temas sobre violência e saúde publicados nas revistas C\&SC, CSP, RSP, AJPH e PAJPH no período de 1996 a 2019.

\begin{tabular}{|c|c|c|c|c|c|c|c|c|c|c|}
\hline \multirow{2}{*}{ Temas abordados } & \multicolumn{2}{|c|}{ C\&SC } & \multicolumn{2}{|c|}{ CSP } & \multicolumn{2}{|c|}{ RSP } & \multicolumn{2}{|c|}{ AJPH } & \multicolumn{2}{|c|}{ PAJPH } \\
\hline & n & $\%$ & $\mathbf{n}$ & $\%$ & $\mathbf{n}$ & $\%$ & $\mathbf{n}$ & $\%$ & $\mathbf{n}$ & $\%$ \\
\hline Causas externas & 128 & 34,2 & 59 & 24,9 & 43 & 27,7 & 94 & 32,2 & 50 & 41,3 \\
\hline Atenção a pessoas em situação de violência* & 63 & 16,8 & 12 & 5,1 & 5 & 3,2 & 3 & 1,0 & 4 & 3,3 \\
\hline Violência intrafamiliar & 44 & 11,8 & 51 & 21,5 & 47 & 30,3 & 40 & 13,7 & 23 & 19,0 \\
\hline Violência de gênero e contra grupos vulneráveis & 33 & 8,8 & 54 & 22,8 & 18 & 11,6 & 93 & 31,8 & 20 & 16,5 \\
\hline Transtornos mentais & 24 & 6,4 & 13 & 5,5 & 14 & 9,0 & 17 & 5,8 & 2 & 1,7 \\
\hline Estudos teóricos/metodológicos & 18 & 4,8 & - & - & - & - & - & - & - & - \\
\hline Notificação/Monitoramento e Vigilância das violências & 17 & 4,5 & 12 & 5,1 & 15 & 9,7 & 6 & 2,1 & 5 & 4,1 \\
\hline Violência e escola & 17 & 4,5 & 10 & 4,2 & 9 & 5,8 & 9 & 3,1 & 7 & 5,8 \\
\hline Violência social em geral ${ }^{* *}$ & 16 & 4,3 & 18 & 7,6 & 2 & 1,3 & 23 & 7,9 & 4 & 3,3 \\
\hline Criminalidade e delinquência & 13 & 3,5 & 3 & 1,3 & - & - & 5 & 1,7 & 5 & 4,1 \\
\hline Violência nas mídias & 1 & 0,3 & 5 & 2,1 & 2 & 1,3 & 2 & 0,7 & 1 & 0,8 \\
\hline
\end{tabular}

* Inclui atendimento; intervenção; análise de políticas; avaliação de serviços e prevenção da violência; ${ }^{\star \star}$ Inclui violência coletiva; migração forçada; tráfico de pessoas; violência urbana; violência e/ou exploração sexual. 
Tabela 2. Características dos artigos sobre violência publicados na revista C\&SC, no período de 1996 a 2019.

\begin{tabular}{|c|c|c|}
\hline Variável & $\mathbf{n}$ & $\%$ \\
\hline \multicolumn{3}{|l|}{ Grande área do conhecimento } \\
\hline Ciências da Saúde & 229 & 61,2 \\
\hline Ciências Humanas & 51 & 13,6 \\
\hline Ciências Sociais Aplicadas & 1 & 0,3 \\
\hline $\begin{array}{l}\text { Ciências da Saúde e Ciências } \\
\text { Humanas }\end{array}$ & 83 & 22,2 \\
\hline $\begin{array}{l}\text { Ciências da Saúde e Ciências Sociais } \\
\text { Aplicadas }\end{array}$ & 5 & 1,3 \\
\hline $\begin{array}{l}\text { Ciências sociais aplicadas e ciências } \\
\text { humanas }\end{array}$ & 1 & 0,3 \\
\hline $\begin{array}{l}\text { Ciências da Saúde, Ciências Sociais } \\
\text { Aplicadas e Ciências Humanas }\end{array}$ & 4 & 1,1 \\
\hline \multicolumn{3}{|l|}{ Região da Instituição* } \\
\hline Norte & 1 & 0,2 \\
\hline Nordeste & 141 & 29,8 \\
\hline Sudeste & 142 & 30,0 \\
\hline Sul & 29 & 6,1 \\
\hline Centro Oeste & 6 & 1,3 \\
\hline $\begin{array}{l}\text { Parcerias entre instituições de mais } \\
\text { de uma região }\end{array}$ & 90 & 19,0 \\
\hline $\begin{array}{l}\text { Parcerias entre instituições nacionais } \\
\text { e internacionais }\end{array}$ & 19 & 4,0 \\
\hline $\begin{array}{l}\text { Instituições/Organismos } \\
\text { Internacionais }\end{array}$ & 45 & 9,5 \\
\hline \multicolumn{3}{|l|}{ Abrangência do estudo } \\
\hline Municipal & 161 & 43,0 \\
\hline Estadual & 28 & 7,5 \\
\hline Nacional & 125 & 33,4 \\
\hline Internacional & 47 & 12,6 \\
\hline Não se aplica & 13 & 3,5 \\
\hline \multicolumn{3}{|l|}{ Método empregado } \\
\hline Quantitativo & 182 & 48,7 \\
\hline Qualitativo & 136 & 36,4 \\
\hline Ambos & 56 & 15,0 \\
\hline \multicolumn{3}{|l|}{ População estudada } \\
\hline Criança/adolescente/jovem & 114 & 30,5 \\
\hline Homem & 7 & 1,9 \\
\hline Mulher & 34 & 9,1 \\
\hline Idoso & 45 & 12,0 \\
\hline Categoria profissional & 40 & 10,7 \\
\hline População em geral & 89 & 23,8 \\
\hline Outros grupos & 15 & 4,0 \\
\hline Não se aplica & 30 & 8,0 \\
\hline
\end{tabular}

região Sudeste foram responsáveis sozinhas pela publicação de 142 artigos; o Nordeste, por 141; o Sul contribuiu com 29, o Centro Oeste, com seis; e a região Norte com uma publicação. Parcerias entre instituições nacionais e internacionais foram observadas em 19 artigos do acervo.

Entre as várias instituições destacam-se: a Fiocruz, a Universidade de São Paulo, a Universidade Federal de Minas Gerais, a Universidade Federal do Rio Grande do Sul, a Universidade de Fortaleza e a Universidade de Brasília. O Ministério da Saúde colaborou em 35 trabalhos. Secretarias estaduais ou municipais de saúde participaram ou desenvolveram inteiramente 29 artigos. Quarenta e três por cento dos estudos abrangeram dados municipais, 33,4\% envolveram dados nacionais e $12,6 \%$, internacionais.

Os métodos quantitativos destacam-se (48,7\%), sobretudo em estudos exploratórios (96 trabalhos) e inquéritos (52 trabalhos). Foram encontrados 29 artigos de revisão. As metodologias qualitativas foram mais diversificadas, como: autopsia psicossocial, estudo etnográfico, estudo documental, estudo de caso, dentre outros. Vale mencionar que 15\% dos artigos envolveram ambas abordagens metodológicas.

Crianças/adolescentes e jovens foram estudadas em 30,5\% dos trabalhos. Além desses, 23,8\% dos artigos focalizaram a população em geral, $12,0 \%$ os idosos, e $10,7 \%$ dirigiram-se a categorias profissionais. A mulher foi foco de 9,1\% dos trabalhos e apenas um abordou o grupo das gestantes. Indígenas, migrantes, presidiários, usuários de drogas, $\mathrm{LGBTI}^{+}$, entre outros, foram alvo de apenas uma ou duas publicações, cada.

Merece destaque o uso de dados do Sistema de Informações sobre Mortalidade/SIM, com 45 publicações, do Sistema de Informações Hospitalares/SIH, em 10, e do Sistema Nacional de Agravos de Notificação/SINAN, em 37 artigos.

\section{Análise dos temas e subtemas específicos}

As causas externas, conjunto de eventos que reúne os acidentes (inclusive os de transporte terrestre) e as violências (auto e heteroinfligidas), incluídos na Classificação Internacional de Doenças, em sua 10a revisão (CID-10), foi a categoria mais representada nas publicações $(34,2 \%)$. Não à toa, pois foram os crescentes indicadores epidemiológicos, letais e não letais desses eventos que, desde a década de 1980, mostraram a importância da violência na morbimortalidade da população brasileira.

Os artigos sobre causas externas (128) estiveram presentes ao longo de todo o período analisado e cresceram numericamente, sobretudo a partir da segunda década dos anos 2000 (Gráfico 
2). Assim, a análise desdobrou o conjunto das publicações sobre causas externas nos seus principais subtemas.

No ano de 2005, a revista C\&SC inaugura as publicações sobre causas externas, quando Laurenti et al. ${ }^{5}$ traçam o perfil epidemiológico da morbimortalidade masculina comparado à feminina. $\mathrm{Na}$ análise, as doenças do aparelho circulatório são a primeira causa de mortes e os acidentes e violências são a segunda. E em 2006, publicou o texto seminal de Concha-Eastman e $\mathrm{Malo}^{6}$, no qual apresentam a proposta da Organização Pan-Americana de Saúde/OPAS para a prevenção da violência, baseada nas recomendações do "Informe mundial sobre violência e saúde" da $\mathrm{OMS}^{7}$. Concha-Eastman e Malo ${ }^{6}$ mostram que o tema já havia sido assumido pelo setor saúde, porém não tinha lugar de destaque entre os agravos à saúde da população. Finalizam articulando a prevenção da violência com as metas do Milênio.

Os artigos de Spinelli et al. ${ }^{8}$, Franco et al. ${ }^{9}$, Gonzalez-Perez et al. ${ }^{10,11}$ e Aleman et al. ${ }^{12}$ fornecem a visão dos impactos da violência na Argentina, Colômbia, México e no Uruguai, respectivamente. Mostram que a violência que os acomete, embora tenha especificidades, também possui semelhanças nos padrões dos eventos e dos grupos mais acometidos.

Em relação ao Brasil, Souza e Lima ${ }^{13}$ analisam a morbidade e a mortalidade por acidentes e violência no país e em suas capitais. $\mathrm{O}$ artigo destaca as persistentes e elevadas taxas de homicídios e das mortes por ATT, e a disseminação dos homicídios para municípios das regiões metropolitanas e do interior dos Estados. Apontam a maior magnitude da morbidade em relação à mortalidade. Anos após, Moura et al. ${ }^{14}$ estimam taxas de mortalidade por causas externas no Brasil, com dados de 2010, e reafirmam a maior razão de mortalidade entre homens, quase nove vezes maior que a das mulheres, principalmente nas regiões Norte e Nordeste. O risco também é maior entre os mais jovens. Os homens morrem mais por agressões e ATT. Mais recentemente, Saltarelli et al. ${ }^{15}$ analisaram a tendência da mortalidade na população de 5 a 69 anos, residente na região Sudeste e em Unidades Federadas (UF). Identificaram queda da taxa de mortalidade na região Sudeste por causas evitáveis e não evitáveis. As taxas de mortes evitáveis mais elevadas são por doenças crônicas não transmissíveis e causas externas.

Ao menos oito estudos sobre morbidade por violência beberam da fonte das edições de 2009 e 2014 do VIVA Inquérito (componente da Vigilância de Violências e Acidentes/VIVA), entre eles: Rodrigues et al. ${ }^{16}$; Malta et al. ${ }^{17}$; Souto et al. ${ }^{18}$. Essas pesquisas mostraram um precioso conjunto de dados sobre o atendimento aos casos de acidentes e violências em serviços de urgência/ emergência de capitais brasileiras e do Distrito Federal. Essas informações permitiram conhecer as características dos eventos, das vítimas e dos seus agressores. Vale mencionar que também a Pesquisa Nacional de Saúde, de 2013, foi usada em um artigo que descreveu a prevalência de violência cometida por pessoas conhecidas ${ }^{19}$.

Ao longo do período, os artigos trouxeram um conhecimento diversificado sobre a morbimortalidade por causas externas. Descreveram, por exemplo, os perfis dos mais afetados (homens, jovens, negros e pobres), fatores associados

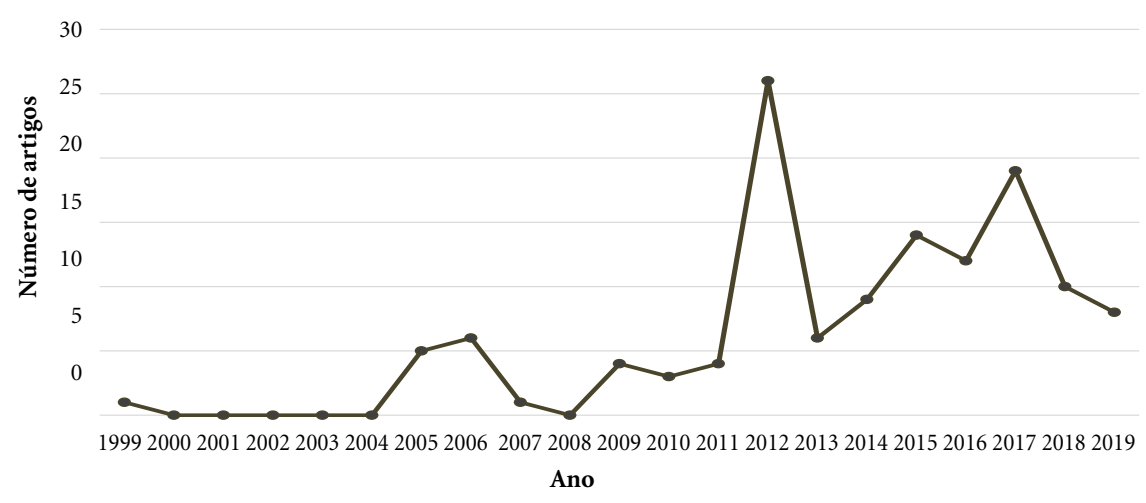

Gráfico 2. Distribuição dos artigos sobre causas externas publicados na revista C\&SC, no período de 1996 a 2019. 
(consumo de álcool, precárias condições socioeconômicas, gênero, uso de arma branca e, sobretudo, de arma de fogo).

O subtema suicídio está representado por 41 artigos ou 32\% das publicações sobre causas externas. Esse tema teve o primeiro artigo publicado pela revista no ano de 2006. Os anos de 2012 e 2015 destacaram-se com maior número de artigos por serem números temáticos. Por outro lado, em pelo menos quatro anos do período não houve nenhuma publicação sobre este tema.

As publicações sobre suicídio indicam que os homens jovens preponderam em termos de mortalidade, pois usam os meios mais letais como enforcamento e arma de fogo, enquanto as mulheres se envolvem mais com as tentativas por meio de uso de substâncias não medicinais, drogas e medicamentos, que são meios menos letais ${ }^{20}$.

Os estudos sobre suicídios e tentativas na adolescência recomendam um redirecionamento das práticas de saúde, demandando que o SUS e a sociedade adotem políticas que valorizem a vida $^{21}$. Além disso, acrescentam a necessidade de repensar e rever a prática médica tendo em vista a subnotificação, a discrepância dos diagnósticos e o não encaminhamento aos órgãos competentes $^{22}$. Destacam as fragilidades e a necessidade de aprimoramento dos dados dos sistemas de informação em geral; a urgência de implantar programas de prevenção e de capacitação dos profissionais dos diferentes níveis de atenção à saúde. Para alguns, as mortes por intoxicação refletem o padrão de consumo dos medicamentos no país e há necessidade de aprimoramento das políticas de vigilância sanitária. Finalmente, ressaltam que a escassez de pesquisas nacionais sobre suicídio na infância pode contribuir para a invisibilidade desse tema e dificultar a instauração de programas de promoção e tratamento de saúde.

O subtema homicídio somou 24 artigos, $18,8 \%$ do conjunto da categoria causas externas. No período dos 25 anos da revista, o primeiro artigo sobre homicídio ocorreu no ano de 2011, após o que passou a constar nas publicações, com exceção dos anos de 2013 e 2015. A maior concentração foi no ano de 2012, com 10 artigos.

Os artigos que caracterizam o perfil das vítimas, o identificam principalmente como homens jovens, dos 15 aos 29 anos, cujas taxas são várias vezes maiores que as do sexo feminino.

Vários fatores são associados à incidência dos homicídios, tais como municípios de maior porte populacional, com maior taxa de fecundidade, baixa proporção de alfabetizados, maior desigualdade e maior urbanização ${ }^{23}$. Peres et al. ${ }^{24}$ observaram associação dos óbitos com taxa de aprisionamento-encarceramento e com atividade policial no município de São Paulo, e concluem que as ações de segurança pública perdem o poder explicativo para a redução dos homicídios após controle da taxa de desemprego e redução na proporção de jovens. Meneghel et al. ${ }^{25}$ encontraram associação negativa entre pobreza e mortes femininas, o que apontam como um paradoxo, pois as mulheres que morrem nas regiões ricas são na maioria pobres. Ainda observaram associação entre violência de gênero, fundamentalismos e violência urbana. Davila e Pardo-Montano ${ }^{26}$ verificaram que o crescimento econômico e a desigualdade se associaram negativamente com a taxa de homicídio, ao passo que o desemprego mostrou relação positiva; a pobreza não teve efeito significativo.

O subtema acidentes de transporte terrestrel ATT foi estudado em 21 artigos (16,4\% das publicações sobre causas externas). Este tema foi primeiramente publicado pela revista em 1999, reaparece em 2005 e depois em 2010, mostrando interrupção ao longo do período analisado.

As publicações sobre os ATT recorrem a várias fontes de dados oriundas das grandes pesquisas nacionais, além de dados do SIM e do atendimento de hospitais de urgência/emergência.

A partir das grandes pesquisas nacionais conseguem verificar as prevalências de importantes variáveis de interesse para o ATT, como o uso de equipamentos de proteção e os comportamentos de risco dos usuários. Envolvem ampla variedade de análises que caracterizam as circunstâncias do evento e o perfil das pessoas nele envolvidas (sobretudo homens jovens) e que são atendidas em serviços de saúde. Identificam tendências temporais; realizam análises espaciais, de associação, de risco e de fatores preditores de ATT. Alguns artigos encontraram associação entre o consumo abusivo e frequente de álcool e a ocorrência de ATT.

O motociclista foi o usuário do trânsito mais estudado, mas outros, como pedestre, ciclista e ocupante de veículo também foram focalizados. Dois artigos abordaram caminhoneiros e motoboys enquanto categorias profissionais.

Em termos de prevenção os autores propõem programas de ação para prevenir acidentes de crianças e adolescentes no trânsito; medidas de prevenção dos acidentes envolvendo motociclistas profissionais; o monitoramento da alcoolemia dos motoristas. Consideram que a magnitude das lesões no trânsito justifica o incentivo e o avanço em medidas preventivas e legislativas para a redução dos ATT. 
ivas apontam o envolvimento da OMS com a segurança no trânsito e a implicação ampliada do setor saúde com o tema. Das contribuições tradicionais, o setor passa a se envolver com a promoção da saúde, com ênfase na intersetorialidade, $\mathrm{e}$ nos aspectos influenciados pela Agenda $2030^{28}$.

O conjunto de artigos (63) que aborda o tema da atenção às pessoas em situação de violência é composto pelos seguintes subtemas: atendimento, intervenção, análise de políticas, avaliação de serviço e prevenção à violência e representa $16,8 \%$ das publicações analisadas. Os artigos publicados concentram-se entre 2009 e 2010. A maioria deles avalia serviços de saúde, analisa políticas e dados provenientes do Sistema de Vigilância dos Acidentes e Violência-VIVA ${ }^{29-32}$. Esses estudos, em geral, buscam caracterizar serviços que atendem às vítimas; realizar diagnósticos situacionais; investigar a participação dos gestores no planejamento de ações, e analisar a implementação de políticas de prevenção da violência. Esses artigos evidenciam a capilaridade da PNMRAV ${ }^{3}$ e o crescimento do número de pesquisadores em diversas regiões do país que se dedicam ao tema da violência. Os trabalhos cujo foco é a prevenção se referem principalmente a adoção dessas ações na atenção primária, pré-hospitalar, hospitalar e de reabilitação. O grupo etário mais abordado é o de crianças, adolescentes e suas famílias em situação de violência. Alguns artigos analisam experiências consolidadas de prevenção às violências, como a do suicídio, e a construção de redes intersetoriais de proteção. Outros artigos focam em profissionais de saúde enquanto atores relevantes para a identificação das diferentes formas de violência.

Ao longo dos 25 anos da revista, 44 artigos focalizaram o tema violência intrafamiliar, o que representa $11,8 \%$ do acervo analisado. Cinco artigos foram publicados no ano de 1999, contudo, entre 2000 e 2008, apenas três trabalhos foram publicados. Nos anos seguintes o tema tem presença constante, mas de pouco vulto, com média de dois artigos por ano e com picos em 2009 e 2019, com cinco publicações em cada. Crianças/ adolescentes, mulheres e idosos são os principais grupos focalizados. Porém, também foram feitos trabalhos direcionados às famílias, profissionais e aos agressores. Os artigos focalizam diversas naturezas da violência (física, psicológica, sexual, negligência), seus impactos e consequências para a saúde e traçam um perfil das vítimas. Destacase, no acervo analisado, o trabalho de Reichenheim et al. ${ }^{33}$, pioneiro na revista no subtema da violência intrafamiliar.

No período analisado foram publicados 33 artigos $(8,8 \%$ do acervo) sobre o tema violência de gênero ou contra grupo vulnerável. O primeiro artigo foi publicado na revista em 2000. Entretanto, ele se manteve quase ausente até 2009, quando seis trabalhos foram publicados, com presença tímida nos anos seguintes. Em 2017 e 2019 publicaram-se, respectivamente, cinco e quatro artigos. A maioria dos estudos focalizou a violência contra a mulher, seja no contexto das relações afetivo-sexuais ou não. Eles abarcaram a coerção sexual, a violência obstétrica, contra mulheres e gestantes encarceradas, contra trabalhadoras e contra mulheres rurais. Indígenas, pessoas com deficiência, crianças institucionalizadas e minorias sexuais, por exemplo, se mostraram pouco presentes na revista ao longo dos anos. Um trabalho envolveu homens autores de violências e outro refletiu sobre a questão da masculinidade e violência. $\mathrm{O}$ único artigo voltado para a população indígena ressalta a maior vulnerabilidade desse grupo frente aos agravos à saúde ${ }^{34}$. Entre os estudos com foco na população $\mathrm{LGBTI}^{+}$, um é uma pesquisa sobre homofobia e vulnerabilidade frente ao HIV/Aids de um grupo de travestis ${ }^{35}$, e o outro é sobre a relação entre bullying homofóbico e autoestima entre jovens de minorias sexuais em Quebéc, Canadáa ${ }^{36}$.

As publicações sobre o tema transtornos mentais (24 artigos) representam $6,4 \%$ do acervo e estão concentradas no ano de 2009. Os estudos referem-se na sua maioria à relação da violência com os transtornos mentais de crianças e adolescentes. Eles são em grande parte estudos nacionais e dois artigos resultam de pesquisas internacionais, uma em Quebec/Canadá ${ }^{37}$, e outra em Chiapas/México ${ }^{38}$. A maioria destaca a necessidade de promoção de políticas públicas de atenção aos problemas de saúde mental, como depressão, comportamento agressivo, ideação e tentativa de suicídio decorrentes de violências. A violência contra a pessoa idosa aparece com destaque para a questão do suicídio e tentativa de suicídio, tendo um estudo da Turquia ${ }^{39}$. Dois estudos de países da América Latina e Caribe abordam a violência política e os efeitos dos conflitos armados na saúde mental da população. Um artigo da 
Colômbia analisa os mecanismos de enfrentamento da população afrodescendente à violência política naquele país ${ }^{40}$.

O tema estudos teóricos/metodológicos foi contemplado com 18 artigos (4,8\% do acervo). Artigos sobre tais questões estiveram presentes em edições da C\&SC desde 1999, porém de modo descontínuo. Nesse ano, os artigos debruçaramse sobre a prevenção das violências na saúde pública, apontando possibilidades e dificuldades para a atuação; o papel das políticas públicas frente à violência estrutural; e, por fim, um diagnóstico dos fatores que permitiram o crescimento da violência criminal no $\mathrm{Brasil}^{41}$. Na esteira da publicação da $\mathrm{PNRMAV}^{3}$ e do Relatório Mundial sobre Violência e Saúde ${ }^{7}$, o segundo fascículo da revista do ano de 2006 trouxe três artigos que refletem esse momento histórico. Um deles traz uma síntese do relatório da OMS, com conceitos e definições, natureza e tipologia da violência e sua abordagem por meio do modelo ecológi$\mathrm{Co}^{42}$. O texto de Wieviorka ${ }^{43}$ contextualiza historicamente a violência contemporânea. Por fim, o artigo de Minayo ${ }^{44}$ trata da inclusão do tema da violência na agenda da saúde, e como este se legitimou a partir da colaboração de diferentes atores como o Ministério da Saúde, movimentos sociais, acadêmicos e profissionais.

Dezessete trabalhos $(4,5 \%)$ tratam do tema da violência e escola Verificam-se estudos que analisaram dados sobre violência das edições de 2009, 2012 e 2015 da Pesquisa Nacional de Saúde do Escolar (PeNSE). O bullying é o tema mais presente nas publicações da revista. De modo geral, todas as publicações indicam a necessidade de ações de prevenção ao bullying tanto no âmbito intramuros quanto extramuros das escolas. Um estudo realizado no México relacionou o bullying à qualidade de vida dos estudantes. Outro artigo abordou as medidas de prevenção à violência na escola no contexto brasileiro e português. Os demais estudos tratam da violência na escola em espaços urbanos, rurais e comunitários, e um constata a presença de lesões maxilofacial em crianças e adolescentes vítimas de violência física no ambiente escolar.

Foram encontrados 17 (4,5\%) artigos sobre o tema notificação/monitoramento/vigilância das violências, dos quais 14 foram publicados a partir de 2012. O primeiro deles, publicado em 1999, focalizou aspectos conceituais e operacionais da vigilância de acidentes e violências ${ }^{45}$, buscando traçar diferenças com a vigilância de outros agravos. Os demais trabalhos incluídos nesta categoria podem ser divididos em três vertentes: (1) uma que focaliza a atuação dos profissionais de saúde no tocante à vigilância de acidentes e violências; (2) outra que analisa dados de vigilância para diferentes públicos (crianças, adolescentes e idosos, especialmente); e (3) uma terceira que engloba trabalhos com foco na qualidade e na confiabilidade dos sistemas.

O tema da violência social, que em geral ainda engloba os subtemas violência coletiva, migração forçada, tráfico de pessoas, violência urbana e violência e/ou exploração sexual, foi representado em 16 artigos (4,3\%) do acervo analisado, porém de forma esporádica. A violência coletiva foi abordada em dois artigos: o primeiro, de 1999, reflete sobre as causas dos eventos violentos de massas, como brigas de torcida de futebol; o segundo, toma como referência grupos étnicos, nacionais, religiosos e ideológicos, cujo pertencimento dos sujeitos iniciou-se na infância, indicando que ameaças à identidade coletiva podem deflagrar episódios de violência das massas e impactar na saúde coletiva. A violência urbana, foi abordada em quatro artigos: (1) analisa a violência a partir do imaginário social das classes mais favorecidas da sociedade; (2) investiga como os jovens das periferias resistem à imagem que relaciona a pobreza à violência; (3) aborda a necessidade de políticas públicas de cuidado a adolescentes que vivem em comunidades de baixa renda dos grandes centros urbanos; (4) analisam os riscos das profissões de policiais militares e civis e as implicações com a saúde desses profissionais em cidades grandes e de médio porte. O subtema da violência sexual e da exploração sexual é tratado em quatro artigos que visam (a) avaliar as ações de programas de prevenção; (b) verificar a associação do abuso sexual com os problemas de saúde mental de crianças e jovens; (c) identificar fatores associados à confirmação do abuso sexual infantil no exame médico legal e, (d) analisar os registros dos exames sexológicos do Instituto de Medicina Legal a fim de evidenciar esse tipo de violência. A problemática das migrações forçadas, do tráfico de pessoas e do trabalho escravo foram raros no período analisado.

O tema da criminalidade e delinquência (13 artigos) está presente em 3,5\% das publicações da revista. Os autores abordam os fatores que levam os jovens a ingressar na criminalidade, mas também os caminhos que os levam a romper com a prática de delitos. Algumas dessas publicações traçam aspectos da delinquência como as questões de gênero, a fim de distinguir a criminalidade masculina da feminina; os contextos demográficos e socioeconômicos, familiares e co- 
munitários da realidade brasileira e da Colômbia. O transtorno mental foi abordado em um artigo que destaca a importância dos serviços de saúde mental na reabilitação dos jovens em conflito com a lei, e em outro que critica a medicalização desses jovens. A relação com o Sistema de Justiça Criminal é analisada em dois artigos: um discute as falhas e as ausências de perícias de cadáveres que possam subsidiar os inquéritos policiais sobre homicídios; e o segundo investiga profissionais do poder judiciário sobre os procedimentos para as entrevistas de crianças e adolescentes nos processos de crimes sexuais. A análise das representações de adolescentes em conflito com a lei na imprensa escrita é objeto de um único estudo. O tema da violência nas mídias enquanto um problema também de saúde pública é uma lacuna no período analisado.

\section{Discussão}

Após a OPAS ter destacado a importância de prevenir a violência nas Américas, nos anos de 1993 e 1994, os Cadernos de Saúde Pública/CSP publicaram em 1994 o número temático O impacto da violência social sobre a saúde, reunindo relevantes estudos, principalmente das áreas das ciências sociais e da epidemiologia. Portanto, historicamente antecederam a divulgação científica do tema no âmbito da saúde pública, comparados à Revista C\&SC, que somente lançou um número temático em 1999.

A maior parte dos estudos publicados produzem informações e conhecimentos sobre a extensão do problema, sua tendência, os perfis socioeconômicos dos grupos vulneráveis, tanto por meio de análises epidemiológicas como pela descrição de dados de registro de serviços. Temas mais abordados pelos métodos qualitativos se ancoram nas teorias sociais, nas representações, nas opiniões e nas percepções dos atores investigados. Alguns são mais estratégicos e buscam dialogar com os serviços e as redes de promoção, prevenção, proteção e atenção.

A população alvo mais estudada foi a de crianças e adolescentes, talvez porque este foi o primeiro grupo em relação ao qual o setor saúde identificou a vitimização por violência, a partir da década de 1960, gerando a criação de serviços de atendimento a esses casos e de proteção a esse grupo.

$\mathrm{O}$ fato de a região Sudeste concentrar grande parte dos estudos publicados pode ser explicado pela existência de um maior número de institui- ções acadêmicas nessa área. Por outro lado, os achados mostram a ínfima produção das regiões Norte e Centro Oeste, o que aponta para a necessidade de incentivo à pesquisa e divulgação de conhecimento científico nessas áreas.

Quanto à abrangência dos estudos, é importante notar que considerável parcela dos artigos é de pesquisas de âmbito municipal, o que mostra a capilaridade do tema no país, e o espaço dado pela revista C\&SC a esses estudos. Estudos locais, tanto quanto os nacionais são fundamentais para subsidiar o planejamento de políticas.

$O$ fato das causas externas ser o tema preponderante nas publicações de quatro entre os cinco periódicos analisados pode ser explicado pela magnitude e crescimento desses eventos no mundo, constituídos, sobretudo, pelos homicídios, acidentes de transporte terrestre e suicídio. Além disso, historicamente, o homicídio está presente como termômetro da violência social. Ressalta-se que desde a década de 70 do século $\mathrm{XX}$, alguns poucos pesquisadores brasileiros da Faculdade de Saúde Pública da Universidade de São Paulo/USP já vinham estudando e publicando artigos sobre as causas externas em periódicos nacionais $^{46,47}$.

Indicadores de causas externas têm sido usados como termômetro das violências que ocorrem nas sociedades. Por isso, estudos de séries históricas que analisem as tendências da morbimortalidade por essas causas em anos mais recentes deveriam ser mais realizados e publicados, levando em consideração grupos específicos e particularmente vulneráveis, como população negra, $\mathrm{LGBTI}^{+}$, indígenas, quilombolas, mulheres, dentre outros. É curioso que só a partir de 2017 apareceram na revista estudos sobre feminicídio ${ }^{48,49}$.

Aspectos como gênero, faixa etária e territórios mais vulneráveis praticamente não foram alvos dos estudos sobre causas externas e homicídio. Esses aspectos, embora sejam determinantes das condições de saúde, tendem a ser mais objeto dos estudos sociais, antropológicos, demográficos ou históricos sobre o tema da violência, predominantemente publicados em periódicos dessas áreas.

São poucos os artigos publicados em relação a homicídios e acidentes de transporte terrestre, comparados à magnitude desses eventos no Brasil. Há anos, em que eles sequer aparecem nas publicações. São incipientes os estudos sobre ATT que abordam a questão do uso de álcool e direção, e inexistem artigos sobre motoristas de ônibus e de aplicativos, por exemplo. É recomen- 
dável publicar estudos que insiram tanto no arcabouço teórico como nas análises, aspectos socioeconômicos e contextuais que ampliem a visão individualizada com que este problema é tratado e permitam ultrapassar a noção de acidentalidade das lesões e mortes provocadas pelo trânsito. Para isso uma perspectiva sistêmica pode ser de grande ajuda. Esse é um ponto que mereceria avançar no debate, assim como no incentivo e apoio às políticas públicas intersetoriais de prevenção à violência em geral, e aos ATT em particular. Contudo, alguns avanços sobre o protagonismo das ações interdisciplinares e intersetoriais da saúde relacionadas ao trânsito são trazidos pela discussão dos Objetivos de Desenvolvimento Sustentável (ODS) da Agenda 203028.

A crítica acima pode ser transposta ao tema do suicídio, em relação ao qual predominam análises que invariavelmente o consideram como questão de transtorno mental dos indivíduos, e raramente ampliam o olhar teórico para levar em conta o contexto social. O tema da automutilação, tão imbricado com as tentativas de suicídio e com o suicídio, não apareceu sequer nos anos mais recentes em nenhum artigo. No decorrer da pandemia da COVID 19, registros de violência doméstica têm aumentado, e é provável que as ideações, as tentativas e os suicídios também tenham se tornado mais frequentes, o que indica a necessidade de estudos que relacionem as formas de violência que se evidenciaram durante essa pandemia.

Os temas da violência de gênero e da intrafamiliar têm sido dos mais estudados no Brasil e no mundo e também se destacam nas publicações, influenciadas tanto pelas elevadas prevalências, como pelas pautas políticas mundiais de defesa dos direitos de mulheres, crianças e adolescentes.

A revista $\mathrm{C} \& S \mathrm{C}$ contribuiu significativamente para a visibilidade do tema da atenção às pessoas em situação de violência no país. Isso evidencia a preocupação do Sistema Único de Saúde e de outras instituições da sociedade em qualificar os serviços e seus profissionais para o atendimento às diversas formas de violência. Entretanto, a descontinuidade e a escassez de estudos sobre as características do atendimento às vítimas impossibilitam verificar como se distribui a rede de serviços de atenção no território nacional, que tipos de atendimentos e intervenções são oferecidos, que grupos sociais têm buscado esses serviços e que indicadores podem servir para ações de prevenção à violência no país.

Finalmente, a análise mostrou que são raras as publicações na C\&SC sobre os temas da violência coletiva; migração forçada; tráfico de pessoas; violência e/ou exploração sexual; mídia e violência, a despeito da gravidade dessas violências para a saúde individual e coletiva, particularmente nas intersecções com as questões de gênero, de faixa etária e de etnia e cor da pele.

\section{Conclusão}

Ao longo dos 25 anos de existência, a revista C\&SC exerceu o importante papel de dar visibilidade ao tema da violência. Esse, por si só, já constitui um motivo de comemoração conjunta para estudiosos e interessados nesse assunto de grande relevância para a saúde pública do país.

Outro ponto a ressaltar como muito positivo são os estudos que utilizaram os sistemas públicos de informação existentes no Brasil e que, a partir dessas análises puderam disseminar dados sobre violência, identificar as características das vítimas, dos agressores e dos tipos de violência. Graças a esses sistemas tornou-se possível obter amplo conhecimento sobre as violências que acometem a população brasileira e subsidiar políticas públicas de prevenção e redução da morbimortalidade por esses eventos. Esses estudos colaboraram, inclusive, para o aprimoramento e a retroalimentação das informações desses sistemas.

Apesar de muitos aspectos positivos, é importante que a revista C\&SC organize chamadas públicas que atentem para as diversas possibilidades de intersecções entre as temáticas, assim como dê visibilidade a alguns temas relevantes no cenário da saúde pública atual.

\section{Colaboradores}

ER Souza, LW Pinto, K Njaine e A Silva participaram de todas as etapas do artigo. 


\section{Referências}

1. Organización Panamericana de la Salud (OPAS). Resolución XIX: Violencia y Salud. Washington: Opas; 1993. (Mimeo)

2. Organización Panamericana de la Salud (OPAS). Salud y Violencia: Plan de Acción Regional. Washington: Opas; 1994. (Mimeo)

3. Brasil. Ministério da Saúde (MS). Portaria GM/MS $\mathrm{n}^{\circ} 737$, de 16 de maio de 2001. Política Nacional de Redução da Morbimortalidade por Acidentes e Violências. Diário Oficial da União 2001; 18 maio.

4. Brasil. Ministério da Saúde (MS). Impacto da violência na saúde dos brasileiros. Brasília: MS; 2005.

5. Laurenti R, Jorge MHPM, Gotlieb SLD. Perfil epidemiológico da morbi-mortalidade masculina. Cien Saude Colet 2005; 10(1):35-46.

6. Concha-Eastman A, Malo M. Da repressão à prevenção da violência: desafio para a sociedade civil e para o setor saúde. Cien Saude Colet 2006; 11(2):339-348.

7. Krug EG, Dahlberg LL, Mercy JA, Zwi AB, Lozano, organizadores. World report on violence and health. Geneva: World Health Organization (WHO); 2002.

8. Spinelli $\mathrm{H}$, Alazraqui M, Zunino G, Hernán O, Poggese $\mathrm{H}$, Concaro C, Porterie S. Mortes e crimes cometidos com armas de fogo na Cidade Autônoma de Buenos Aires, 2002. Cien Saude Colet 2006; 11(Supl.):12351246.

9. Franco S, Suarez CM, Naranjo CB, Báez LC, Rozo P. Efeitos do conflito armado sobre a vida e a saúde na Colômbia. Cien Saude Colet 2006; 11(2):349-361.

10. González-Pérez GJ, Vega-López MG, Cabrera-Pivaral CE, Vega-López A, Muñoz De La Torre A. Mortalidad por homicidios en México: tendencias, variaciones socio-geográficas y factores asociados. Cien Saude Colet 2012; 17(12):3195-3208.

11. Gonzalez-Perez GJ, Vega-Lopez MG, Flores-Villavicencio ME. El incremento de la mortalidad por armas de fuego y su relación con el estancamiento de la esperanza de vida en México. Cien Saude Colet 2017; 22(9):2861-2872.

12. Aleman A, Colistro V, Colomar M, Cavalleri F, Alegretti $M$, Buglioli $M$. Carga de enfermedad de los adolescentes en Uruguay y su comparación con la de América Latina y el Caribe. Cien Saude Colet 2018; 23(9):2813-2820.

13. Souza ER, Lima MLC. Panorama da violência urbana no Brasil e suas capitais. Cien Saude Colet 2006; 11(2):363-373

14. Moura EC, Gomes R, Falcão MTC, Schwarz E, Neves ACM, Santos W. Desigualdades de gênero na mortalidade por causas externas no Brasil, 2010. Cien Saude Colet 2015; 20(3):779-788.

15. Saltarelli RMF, Prado RR, Monteiro RA, Machado IE, Teixeira BSM, Malta DC. Mortes evitáveis por ações do Sistema Único de Saúde na população da Região Sudeste do Brasil. Cien Saude Colet 2019; 24(3):887898.

16. Rodrigues CS, Malta DC, Godinho T, Mascarenhas MDM, Silva MMA, Silva RE. Acidentes e violências entre mulheres atendidas em Serviços de Emergência Sentinela - Brasil, 2009. Cien Saude Colet 2012; 17(9):2319-2329.
17. Malta DC, Mascarenhas MDM, Silva MMA, Carvalho MGO, Barufaldi LA, Avanci JQ, Bernal RTI. A ocorrência de causas externas na infância em serviços de urgência: aspectos epidemiológicos, Brasil, 2014. Cien Saude Colet 2016; 21(12):3729-3744.

18. Souto RMCV, Barufaldi LA, Nico LS, Freitas MG Perfil epidemiológico do atendimento por violência nos serviços públicos de urgência e emergência em capitais brasileiras, Viva 2014. Cien Saude Colet 2017; 22(9):2811-2823.

19. Mascarenhas MDM, Sinimbu RB, Malta DC, Silva MMA, Santos AF, Vieira MLFP, Szwarcwald CL. Violência cometida por pessoa conhecida - Brasil, 2013. Cien Saude Colet 2017; 22(11):3763-3772.

20. Souza ER, Minayo MCS, Cavalcante FG. O impacto do suicídio sobre a morbimortalidade na população de Itabira. Cien Saude Colet 2006; 11(2):409-418.

21. Vieira LJES, Freitas MLV, Pordeus AMJ, Lira SVG, Silva JG. "Amor não correspondido": discursos de adolescentes que tentaram suicídio. Cien Saude Colet 2009; 14(5):1825-1834.

22. Alves MAG, Cadete MMM. Tentativa de suicídio infanto-juvenil: lesão da parte ou do todo? Cien Saude Colet 2015; 20(1):75-84.

23. Duarte EC, Garcia LP, Freitas LRS, Mansano NH, Monteiro RA, Ramalho WM. Associação ecológica entre características dos municípios e o risco de homicídios em homens adultos de 20-39 anos de idade no Brasil, 1999-2010. Cien Saude Colet 2012; 17(9):22592268.

24. Peres MFT, Almeida JF, Vicentin D, Ruotti C, Nery MB, Cerda M, Cardia N, Adorno S. Evolução dos homicídios e indicadores de segurança pública no $\mathrm{Mu}$ nicípio de São Paulo entre 1996 a 2008: um estudo ecológico de séries temporais. Cien Saude Colet 2012; 17(12):3249-3257.

25. Meneghel SN, Rosa BAR, Ceccon RF, Hirakata VN, Danilevicz IM. Feminicídios: estudo em capitais e municípios brasileiros de grande porte populacional. Cien Saude Colet 2017; 22(9):2963-2970.

26. Davila CA, Pardo-Montano AM. Factores socioeconómicos asociados con la mortalidad por homicidios en Colombia, 2000-2014. Cien Saude Colet 2019; 24(8):2793-2804.

27. Pavarino Filho RV. As Declarações de Moscou e Brasília sobre a segurança no trânsito - um paralelo entre dois momentos no tema da saúde. Cien Saude Colet 2016; 21(12):3649-3660

28. United Nations General Assembly. Transforming our world: the 2030 Agenda for Sustainable Development, 21 October 2015, A/RES/70/1. [document on the Internet].2015 Oct. [cited 2020 Jun 7] Available at: https://www.refworld.org/docid/57b6e3e44.html

29. Brasil. Ministério da Saúde (MS). Viva: vigilância de violências e acidentes, 2006 e 2007. Brasília: MS; 2009. [acessado 2020 Jun 7]. Disponível em: http://bvsms. saude.gov.br/bvs/publicacoes/viva_vigilancia_violencias_acidentes.pdf.

30. Brasil. Ministério da Saúde (MS). Viva: vigilância de violências e acidentes, 2008 e 2009. Brasília: MS; 2010. [acessado 2020 Jun 7]. Disponível em: http://bvsms. saude.gov.br/bvs/publicacoes/viva_2008_2009_violencias_acidentes.pdf 
31. Brasil. Ministério da Saúde (MS). Viva: vigilância de violências e acidentes, 2009, 2010 e 2011. Brasília: MS; 2013. [acessado 2020 Jun 7]. Disponível em: http://bvsms.saude.gov.br/bvs/publicacoes/viva_ 2009_2011_versao_eletronica.pdf

32. Brasil. Ministério da Saúde (MS). Viva: Vigilância de Violências e Acidentes: 2013 e 2014 [recurso eletrônico]. Brasília: MS; 2017. [acessado 2020 Jun 7]. Disponível em: https://bvsms.saude.gov.br/bvs/publicacoes/viva_vigilancia_violencia_acidentes_2013_2014. pdf

33. Reichenheim ME, Hasselmann MH, Moraes CL. Consequências da violência familiar na saúde da criança e do adolescente: contribuições para a elaboração de propostas de ação. Cien Saude Colet 1999; 4(1):109121.

34. Coimbra Júnior CEA, Santos RV. Saúde, minorias e desigualdade: algumas teias de inter-relações, com ênfase nos povos indígenas no Brasil. Cien Saude Colet 2000; 5(1):125-132.

35. Sousa PJ, Ferreira LOC, Sá JB. Estudo descritivo da homofobia e vulnerabilidade ao HIV/Aids das travestis da Região Metropolitana do Recife, Brasil. Cien Saude Colet 2013; 18(8):2239-2251.

36. Blais M, Gervais J, Hebert M. Homofobia internalizada como mediador parcial do bullying homofóbico e autoestima entre jovens de minorias sexuais em Quebec (Canadá). Cien Saude Colet 2014; 19(3):727-735.

37. Hebert M, Lavoie F, Blais M. Post Traumatic Stress Disorder/PTSD in adolescent victims of sexual abuse: resilience and social support as protection factors. Cien Saude Colet 2014; 19(3):685-694.

38. Lara GAG, Zúñiga JO, Pérez OC, Solís SH, Jiménez CEP, Méndez MC. Variables predictoras de la ideación suicida y sintomatología depresiva en adolescentes de Chiapas, México. Cien Saude Colet 2018; 23(4):10891096.

39. Aslan M, Hocaoglu C, Bahceci B. Description of suicide ideation among older adults and a psychological profile: a cross-sectional study in Turkey. Cien Saude Colet 2019; 24(5):1865-1874.

40. Bonilla-Escobar FJ, Osorio-Cuellar GV, PacichanaQuinayáz SG, Sánchez-Rentería G, Fandiño-Losada A, Gutiérrez MI. Do not forget culture when implementing mental health interventions for violence survivors. Cien Saude Colet 2017; 22(9):3053-3059.

41. Chesnais JC. A violência no Brasil: causas e recomendações políticas para a sua prevenção. Cien Saude Colet 1999; 4(1):53-69.
42. Dahlberg LL, Krug EG. Violência: um problema global de saúde pública. Cien Saude Colet 2006; 11(Supl.):1163-1178.

43. Wieviorka M. Violência hoje. Cien Saude Colet 2006; 11(Supl.):1147-1153.

44. Minayo MCS. A inclusão da violência na agenda da saúde: trajetória histórica. Cien Saude Colet 2006; 11(Supl.):1259-1267.

45. Waldman EA, Mello Jorge MH. Vigilância para acidentes e violência: instrumento para estratégias de prevenção e controle. Cien Saude Colet 1999; 4(1):7179.

46. Mello Jorge MHP, Gotlieb SLD. Acidentes, envenenamentos e violências como causa de morte no município de São Paulo. Rev Saude Publica 1976; 10(1):45-55.

47. Mello Jorge, MHP. Mortalidade por causas violentas no Município de São Paulo [tese]. São Paulo: Universidade de São Paulo; 1979.

48. Souza ER, Meira KC, Ribeiro AP, Santos J, Guimarães RM, Borges LF, Oliveira LV, Simões TC. Homicídios de mulheres nas distintas regiões brasileiras nos últimos 35 anos: análise do efeito da idade-período e coorte de nascimento. Cien Saude Colet 2017; 22(9):2949-2962.

49. Leite FMC, Mascarello KC, Almeida APSC, Fávero JL, Santos AS, Silva ICM, Wehrmeister FC. Análise da tendência da mortalidade feminina por agressão no Brasil, estados e regiões. Cien Saude Colet 2017; 22(9):2971-2978.

Artigo apresentado em 10/06/2020

Aprovado em 16/06/2020

Versão final apresentada em 18/06/2020 